\title{
Parsiyel ÖÇB yaralanmalarının tedavisi
}

\section{The treatment of partial anterior cruciate ligament injuries}

\author{
Yavuz Kocabey ${ }^{1}$, Gökhan Polat ${ }^{2}$ \\ ${ }^{1}$ Kocaeli Acıbadem Hastanesi Ortopedi ve Travmatoloji Kliniği, Kocaeli

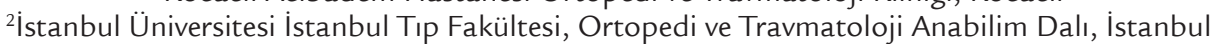

\begin{abstract}
Ön çapraz bağ (ÖÇB) yaralanmalarının yaklaşık \%25’inin parsiyel yaralanmalar olduğu tahmin edilmektedir. Yapılan anatomik ve biyomekanik çalışmaların neticesinde ÖÇB'nin fonksiyonel açıdan anteromedial (AM) ve posterolateral (PL) demetlerden oluştuğu gösterilmiştir. Parsiyel ÖÇB yaralanmalarının tanımı, tanısı ve doğal gidişatı konusu halen tartışmalıdır. Literatürde parsiyel yaralanma; kalan ÖÇB dokusunun $\% 50$ 'den fazla olup olmaması, manyetik rezonans incelemede kısmi devamlılık kaybı olması, artroskopik değerlendirmede $A M$ ve $P L$ demetlerin anatomik femoral yapışma yerinde bulunup bulunmaması gibi farklı kriterlerle tanımlanmıştır. Muayene bulguları silik olan fonksiyonel açıdan düşük beklentili hastaların bir kısmında konservatif olarak izlenerek iyi sonuçlar elde edilebilir. Buna rağmen doğal seyre ait yapılan çalışmalarda genç aktif bireylerde, bağın \%50'ye varan oranlarda total rüptüre ilerlediği ve klinik instabilite gelişebildiği de ortaya konulmuştur. Bu açıdan genç yüksek beklentili hastalarda ya da ek lezyonu olan hastalarda patolojinin cerrahi olarak tedavisi daha akıllıca olacaktır. Cerrahi tedavide termal modifikasyon, tek demet tamir, selektif tek demet rekonstrüksiyon ya da total anatomik rekonstrüksiyon tarif edilmiştir. Literatürde bu yaralanmaların cerrahi tedavisinde hasta bazlı bir değerlendirme yapılması ve karar verilmesi önerilmektedir. Tedavide yaralanmanın tipi ve cerrahın tercihine göre uygun yaralanmalarda, selektif tek demet rekonstrüksiyon ya da total anatomik rekonstrüksiyonun uygulanabilir.
\end{abstract}

Anahtar sözcülkler: parsiyel ön çapraz bağ yaralanması; anteromedial demet; posterolateral demet; rotasyonel instabilite; tek demet rekonstrüksiyon
$25 \%$ of the anterior cruciate ligament ( $A C L$ ) injuries are estimated as partial injuries. According to the anatomical and biomechanical studies, ACL is divided as anteromedial (AM) bundle and posterolateral (PL) bundle functionally. The definition, diagnosis and natural course of partial $A C L$ injuries are still controversial. In the literature, partial injury of $A C L$ was described with different definitions like more than $50 \%$ intact $A C L$, the loss of continuity of $A C L$ in magnetic resonance imaging, the loos of contact to the femoral footprint of AM or PL bundles in arthroscopic assessment. In some of these patients who has obscure clinical instability findings and low functional demands, there are good results with conservative treatment. However, according to studies regarding the natural course of the disease in young and active patients, the partial $\mathrm{ACL}$ rupture can be advanced to total rupture nearly in $50 \%$ of the patients. For this reason, in high demanding patients or patients who had additional intraarticular pathologies, the surgical treatment of partial $A C L$ rupture will be more sensible. In the surgical treatment; thermal modification, single bundle repair, selective single bundle reconstruction and total anatomic $A C L$ reconstruction have been described. In the literature for the choice of treatment, it is recommended that each patient should be evaluated individually. In the surgical treatment, a selective single bundle reconstruction or total anatomic ACL reconstruction can be performed according to the partially injured site and surgeon's preference.

Key words: partial anterior cruciate ligament reconstruction; anteromedial bundle; posterolateral bundle; rotational instability; single bundle reconstruction

\section{Ö} n çapraz bağ (ÖÇB) yaralanmaları sık görülen spor yaralanmalarından biridir ve bu yaralanmaların yaklaşık \%25'inin parsiyel yaralanmalar olduğu tahmin edilmektedir. ${ }^{[1]}$ Bu yaralanmanın tanımı ve tedavisi konusunda tam bir fikir birliği olmamakla birlikte, fizik muayenede sert sonlanmanın eşlik ettiği göreceli artmış öne translasyon ve manyetik rezonans (MR) incelenmesinde ÖÇB'nin kısmi devamlılık kaybı olarak tanımlanabilir. ${ }^{[2,3]}$
Parsiyel ÖÇB yaralanmalarının tanısı ve doğal gidişatı konusu halen tartışmalıdır. Muayene bulguları silik olan bu hastaların bir kısmı konservatif olarak izlenerek iyi sonuçlar elde edilebilir. Buna rağmen bazı asemptomatik yüksek beklentili hastalarda tek demet ya da total rekonstrüksiyon gerekli olabilmektedir. Teknik olarak daha zor olmasına rağmen tek demet rekonstrüksiyon (augmentasyon) bağın propriyoseptif duyusunun korunmasının yanında, daha iyi bir rotasyonel

- Iletişim adresi: Prof. Dr. Yavuz Kocabey, Kocaeli Acıbadem Hastanesi Ortopedi ve Travmatoloji Kliniği, Kocaeli

Tel: 0537 - 2367367 e-posta: drkocabey@yahoo.com

- Geliș tarihi: 30 Nisan $2020 \quad$ Kabul tarihi: 14 Mayıs 2020 

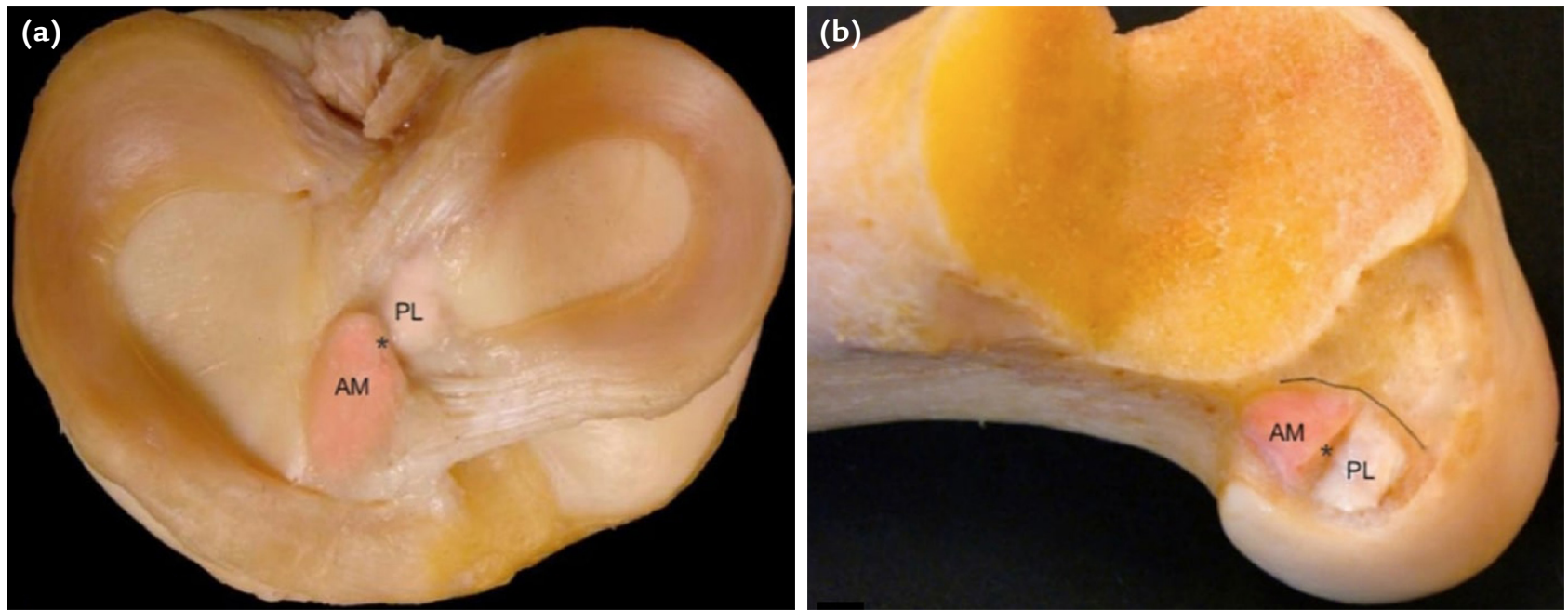

Şekil 1. a, b. Ön çapraz bağın tibial (a) ve femoral (b) ayak izlerinin görünümü (AM, anteromedial demet; PL, posterolateral demet).

stabilite sağlayabilmektedir. ${ }^{[4]}$ Buna rağmen literatürde, tek demet rekonstrüksiyonun mu, primer anatomik rekonstrüksiyonun mu daha üstün olduğu halen tartışmalıdır. ${ }^{[5]}$

\section{ANATOMI VE BIYOMEKANIK}

ÖÇB anatomisine ait çalışmalar, bağın homojen tübüler bir yapıya sahip olmadığını ve fonksiyonel açıdan anteromedial $(\mathrm{AM})$ ve posterolateral $(\mathrm{PL})$ olarak adlandırılan iki fonksiyonel demetten oluştuğunu göstermiştir. Demetlerin isimlendirilmesi, tibial yapışma yerlerine göre yapılmıştır. AM demet, tibiada PL demetin anteriorunda ve medialinde konumlanır. Bununla birlikte femoral yapışma yerinde AM demet, PL demetin proksimaline yapışmaktadır (Şekil 1). ${ }^{[6]}$

Fonksiyonel açıdan diz eklemi fleksiyona gelirken AM demet gerginleşmekte, PL demet gevşemektedir. Bunun yanında diz eklemi ekstansiyona gelirken PL demet gergin hale gelirken AM demet ise gevşemektedir. Diz eklemi biyomekaniğindeki bu dönüşümlü gerginlik, AM demetin ya da PL demetin sınırlı bir travma sonucunda yaralanabileceğini ortaya koymaktadır. ${ }^{[7,8]}$ Bu durumda ÖÇB'nin parsiyel yaralanmasında, yaralanma esnasında diz ekleminin fleksiyon derecesi ve travmanın şiddeti ön plana çıkmaktadır. AM demet daha izometrik bir yapıdadır ve yaralandığı durumlarda öne translasyonun arttığı, buna rağmen daha oblik olan PL demetin izometrik olmadığı ve yaralandığında diz eklemi rotasyonel stabilitesinin daha fazla etkilendiği ortaya konulmuştur. Buna rağmen yaralanmanın izole bir demeti etkilemediği yaralanma mekanizmaları olduğu unutulmamalıdır. ${ }^{[7-9]}$

\section{Yaralanma Sonrası Doğal Seyir}

Parsiyel yırtıklar sırasında, makroskopik olarak intakt duran ligamentte, interstisyel yaralanmaya bağlı olarak \%50'yi geçebilen bir uzama görülebilmektedir. Bu durumda görüntülemelerde ligament intakt gözükse de fonksiyonunu kaybedebilmektedir.[10,11] ÖÇB'nin kanlanması temelde epiligamentöz dokudan gelmektedir ve yaralanma sonrası iyileşme kapasitesi oldukça sınırlıdır. Bu açıdan yaralanma sonrası intakt olan dokunun iskemik nekrozu sonrasında parsiyel yaralanmanın totale dönüşmesi görülebilmektedir. Yetersiz iyileşme kapasitesi dışında parsiyel hasarlı bağın mikroskopik hasarı, doğal seyir içerisinde ilerleyen dönemde tekrarlayan instabilite, sekonder meniskal ve kondral hasar ile kendini gösterebilmektedir. ${ }^{[10,11]}$

\section{Yaralanmanın Tanımı ve Tanı}

Yaralanmanın tanımı üzerinde kesin bir fikir birliği (konsensus) yoktur. ${ }^{[2]}$ Noyes tarafından kalan ÖÇB miktarına göre tanımlanmış, Crain tarafından artroskopik değerlendirmeye göre, Defranko ve Bach'a göre klinik, diz laksitesi ve artroskopik değerlendirme kriterlerine göre tanımlanmıştır. ${ }^{[2]}$ Tarihsel süreç içerisinde değişik otörler tarafindan; kalan ÖÇB dokusunun \%50'den fazla olup olmaması, artroskopik değerlendirmede $A M$ ve PL demetin anatomik femoral yapışma yerinde bulunup bulunmaması gibi kriterler göz önünde bulundurularak çalışmalar yapılmıştır. ${ }^{[2]}$ Parsiyel yaralanma; sağlam tarafa kıyasla asimetrik tibial öne translasyon varlığı, negatif pivot shift testi, 3 ya da 4 mm'den daha düşük artrometrik test sonucu ve ÖÇB'nin yaralandığının artroskopik kanıtı gibi birkaç faktörün kombinasyonu olarak tanımlanabilir. ${ }^{[1,2]}$ 

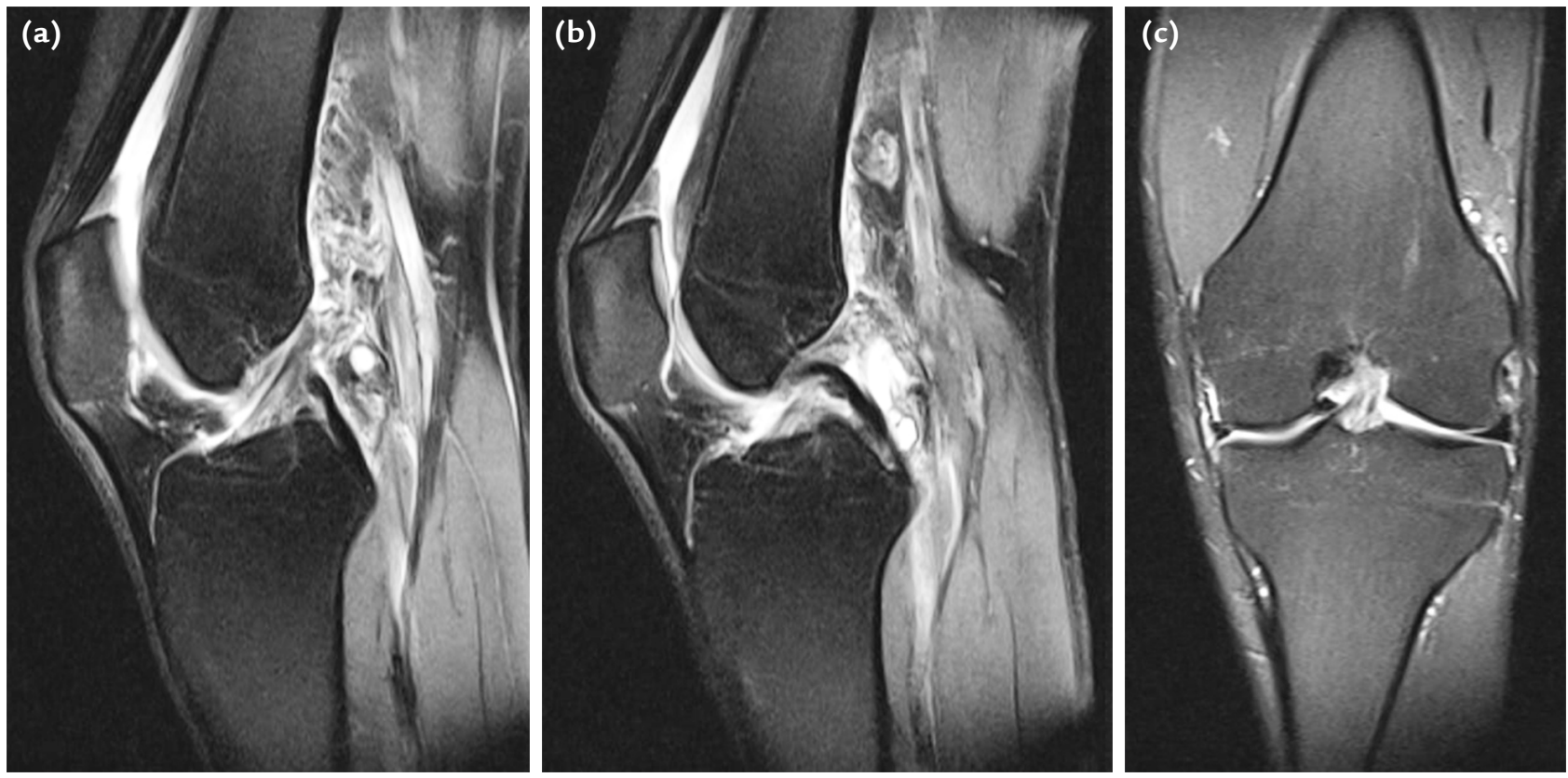

Şekil 2. a-c. Otuz yaşında, sol dizinde kilitlenme ve hemartrozu mevcut olan hastanın, seri sagittal MR kesitlerinde AM demetin sağlam olduğu ve PL demetin izlenmediği görülmekte $(\mathbf{a}, \mathbf{b})$. Koronal kesitte AM demetin devamlılığı görülmekle birlikte, lateral femoral kondil PL demet yapışma yerinin boş olduğu görülmekte (c).

Parsiyel ÖÇB yaralanması tanısında, hastadan alınan ayrıntılı anamnez, ayrıntılı ve titiz bir fizik muayene kilit öneme sahiptir. Yaralanma sıklıkla temassız bir şekilde, sabit alt ekstremite üzerinde femurun eksternal rotasyonu ve valgus momenti sonucu gelişir. Diz ekleminde hemartroz her zaman görülmeyebilir. ${ }^{[1,2]}$

Fizik muayenede tüm testler yaralanmamış ekstremite ile karşılaştırmalı yapılmalıdır. Hemartroz ya da effüzyon varlığ, alt ekstremite atrofisi, diz eklemi hareket açıklığı not edilmelidir. Anatomik belirteç noktalar palpasyonla değerlendirilmeli, şüpheli bir durumda spesifik instabilite ya da menisküs testleri uygulanmalıdır. $^{[1,2]}$ Anterior-posterior stabilite değerlendirilmesi ön çekmece testi, Lachman testi ve Lever bulgusu ile değerlendirilebilir. Öne translasyonda sağlam tarafa göre 3 mm'den daha az bir artış izole AM demet yaralanması açısından şüphe uyandırmalıdır. Bununla birlikte diz eklemi rotasyonel stabilitesinde en önemli gösterge pivot shift testidir. ${ }^{[1]}$ Yapılan çalışmalarda parsiyel yırtıkların değerlendirmesinde Grade 1 pivot shift testinin PL demetin etkilendiği parsiyel yırtıklar için anlamlı olduğu, buna rağmen Grade 2 ya da 3 pivot shift testi olan diz ekleminde, ÖÇB'nin total yaralanmasından şüphe edilmesi gerektiği bildirilmektedir. ${ }^{[1]}$ Parsiyel ön çapraz bağ yaralanmalarında klinik muayene testlerinin güvenilirliği, komplet yırtıklara göre daha düşüktürr. ${ }^{[1,2]} \mathrm{Bu}$ açıdan bu hastaların diz eklemi laksiteleri, KT $1000^{\circledR}$, Telos $^{\circledR}$,
GNRB ${ }^{\circledR}$ knee arthrometer gibi laksite ölçüm cihazları kullanılarak da ölçülebilir. Buna rağmen bu ölçüm cihazlarının total ÖÇB rüptürü olan hastalarda bile sensitivitesi ve spesifisitesi çok yükssek değildir. ${ }^{[2,12]} \mathrm{Bu}$ açıdan radyolojik incelemelerin titizlikle yapılması gereklidir.

MR incelemesi parsiyel ÖÇB yaralanması açısından oldukça değerlidir. Buna rağmen standart diz MR görüntülemeleri ile parsiyel ÖÇB yaralanması tanısı konulması her zaman mümkün olmayabilir. Bu açıdan parasagittal ve parakoronal (oblik) plan görüntüleri alınması gereklidir. Bu görüntülerde ÖÇB'nin kalınlığı, devamlılığı ve sinyal intensitesi değerlendirilmelidir (Şekil 2). ${ }^{[13]}$

\section{TEDAVi}

Tedavi kararında; hastanın yaşı, sportif aktivite seviyesi ve beklentisi, yaralanma zamanı, bağın yaralanma miktarı gibi faktörler göz önünde bulundurularak hasta bazlı olarak değerlendirme yapılmalı ve karar verilmelidir (Şekil 3). ${ }^{[1,2]}$

\section{Konservatif Tedavi}

Sportif olarak düşük beklentili ya da sedanter bir yaşam süren hastalar parsiyel yaralanma sonrasında konservatif olarak izlenebilirler. Bu durumda eklem içi sorun ve olası senaryolar hasta ile paylaşılarak hasta fizik tedavi ve rehabilitasyon eşliğinde izleme alınmalıdır. ${ }^{[1,2,14]}$ 


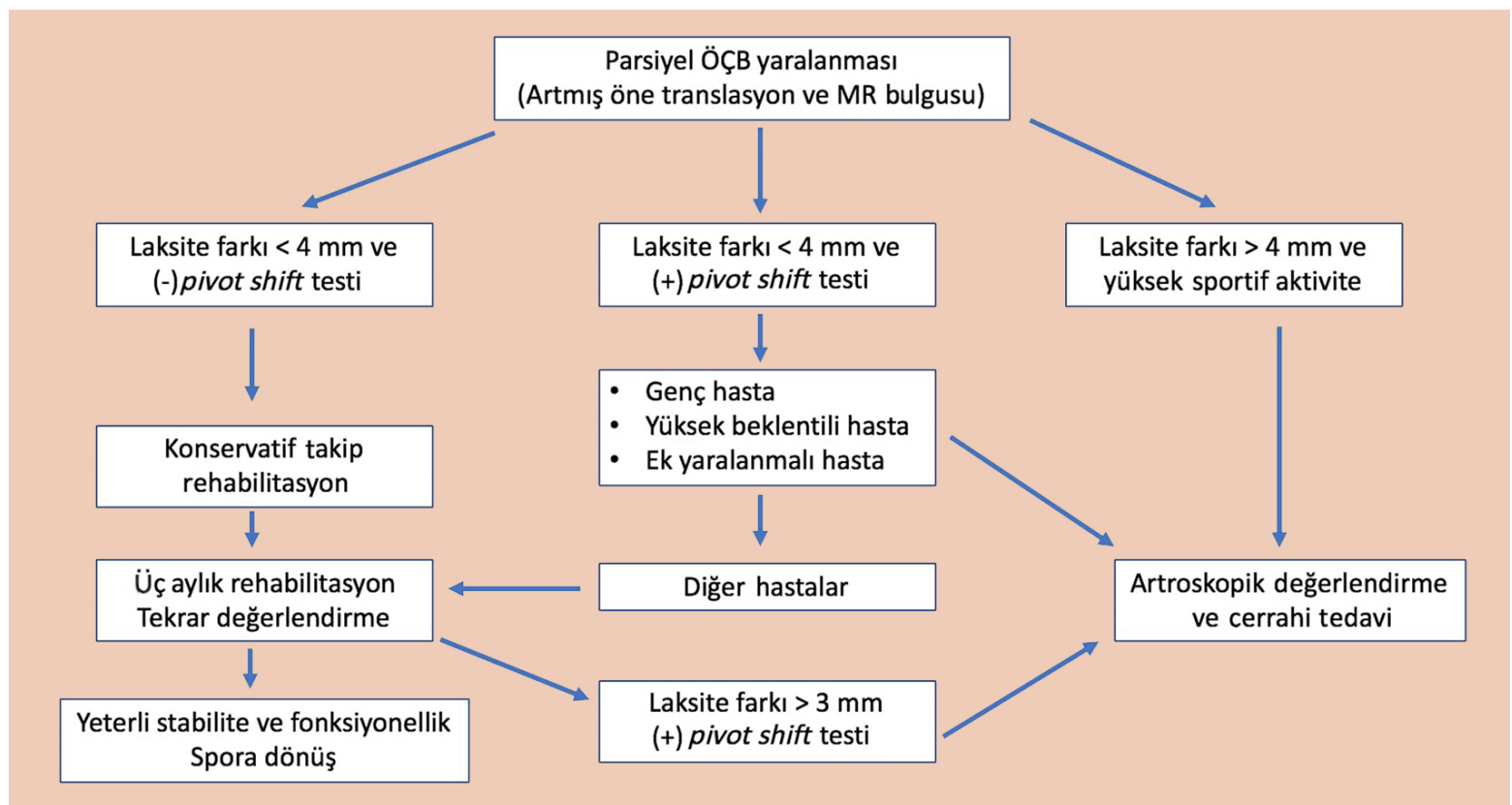

Şekil 3. Parsiyel ÖÇB yaralanmalarında, rutin olarak uygulanacak genel bir konsensus içinde kabul edilmiş bir tedavi algoritması bulunmamaktadır. Sonnery-Cottet ve Colombet tarafından 2016'da yayımlanan tedavi algoritması özetlenmiştir.[2]

Yaralanmanın akut döneminde atel (breys) kullanımının literatürde tedavi sonuçları üzerinde belirgin bir fark yaratmadığı bildirilmektedir. Bu açıdan akut dönemde anti-enflamatuvar tedavinin yanında, hastaların tolere ettikleri yükle yürütülmeleri ve hareket açıklığını geri kazanmaya yönelik fizik tedavi ve rehabilitasyon ile izlenmeleri uygun olacaktır. Genel olarak rehabilitasyon programı; hareket açıklığının ve alt ekstremite kas gücünün tekrar kazanılması sonrasında dayanıklılık ve spora özel egzersizleri içermelidir. Üç aylık takip sonrası hastaların fonksiyonel aktivitelerine dönmeleri planlanır. Tekrarlayan instabilite durumunda cerrahi tedavi düşünülmelidir. ${ }^{[14,15]}$

Son yıllarda rejeneratif tedaviler (trombositten zengin plazma, kemik iliği aspirat konsantresi gibi) iyileşmeyi artırıcı faktör olarak denenmektedir. ${ }^{[16]}$ Buna rağmen literatürde iyileşmeyi artırdığına dair güvenilir bir kanıt bulunmamaktadır.

\section{Cerrahi Tedavi}

Yapılan çalışmalarda genç aktif hastalarda parsiyel yırtıkların \%39'a varan oranlarda total yırtıklara ilerlediği gösterilmektedir. ${ }^{[17]}$ Sportif aktivite düzeyi ve beklentisi yüksek olan hastalarda ve pivot shift testi pozitif olan hastalarda ön planda düşünülmelidir. ${ }^{[1]}$

Tüm muayeneler, karşı diz ile karşılaştırmalı olarak anestezi altında tekrarlanmalıdır. Parsiyel yırtıkların tedavisinde; termal modifikasyon, tek demet tamir, tek demet rekonstrüksiyon (augmentasyon) ve standart anatomik rekonstrüksiyon tarif edilmiştir. ${ }^{[1,2]}$

\section{Termal modifikasyon}

Monopolar radyoferans cihazları yardımıyla hasarlanan dokunun laksitesinin azaltılması ve daha homojen bir doku haline getirilmesi amaçlanır. Literatürde parsiyel yırtıklarda uyguladıkları termal modifikasyon tedavi sonuçlarını başarılı olarak bildiren otörler mevcuttur. ${ }^{[18]}$ Buna rağmen bu tedavinin etkinliği birçok açıdan sorgulanmaktadır ve literatürde bu konuda yüksek kalitede karşılaştırmalı bir yayın bulunmamaktadır. ${ }^{[1]}$

\section{Tek demet tamir}

Son yıllarda ÖÇB yaralanması sonrası tamirin popülarize olması, parsiyel yırtıkların tedavisinde de tek demet tamir uygulamalarını gündeme getirmiştir. Yaralanma olan demetin sentetik sütür materyalleri ile desteklenerek femoral yapışma yerine tekrar tespiti (internal breysleme) uygulanabilmektedir. Femoral tespit için vidalı sütür çapalar ya da kortikal tespit cihazları kullanılabilmektedir. ${ }^{[19]}$ Literatürde rutin uygulama açısından yeterli veri bulunmamaktadır.

\section{Selektif tek demet rekonstrüksiyon}

Bu teknik parsiyel olarak yaralanmış ÖÇB'nin AM ve $\mathrm{PL}$ demetlerinin fonksiyonelliklerinin artroskopik 

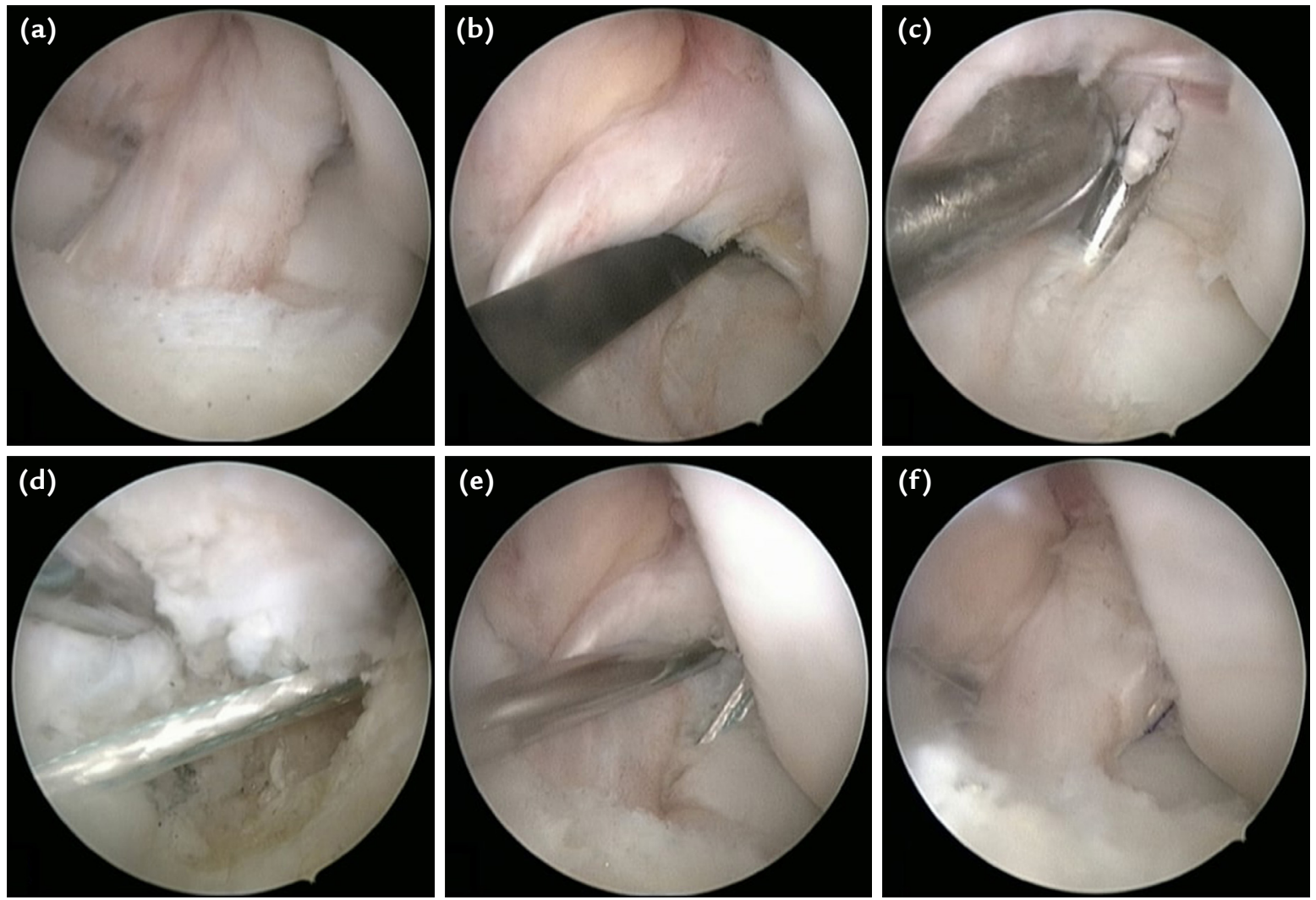

Şekil 4. a-f. Yirmi yaşında erkek hastada, iki ay önce geçirilmiş spor travması; Lachman +, pivot shift ++. Anterolateral portalden alınan artroskopik görüntülerde AM demetin sağlam olduğu, PL demetin ise rüptüre olduğu ve kısmen rezorbe olduğu izlenmekte (a, b). PL demet tibial ayak izine tünel açılması (c). PL demet femoral yapışma yerine açılan tünel izlenmekte (d). Greftin tünele yerleştirilmeden önceki artroskopik görünüm (e). PL demet rekonstrüksiyonu sonrası görünüm (f).

muayene ile tespiti sonrasında, yetmezlik olan demetin anatomik yapışma yerleri göz önünde bulundurularak rekonstrüksiyonunu içerir. Greft materyali olarak en sık otojen hamstring tendonları tercih edilmektedir (Şekil 4).

Literatürde selektif tek demet rekonstrüksiyon sonrası iyi-mükemmel sonuç bildiren birçok çalışma mevcuttur. ${ }^{[20-22]} 2009$ yılında yayımlanan 45 hastalık olgu serisinde, yazarlar selektif AM ve PL demet rekonstrüksiyon uygulamışlardır. İki yıllık takip sonrasında Lysholm diz skorlarında belirgin artış bildirilmiştir. ${ }^{[20]}$ Abat ve ark., selektif tek demet rekonstrüksiyon uyguladıkları 28 hastalık (18 AM demet, 10 PL demet) serilerinde fonksiyonel skorlarda belirgin iyileşme ve iyi-mükemmel sonuç bildirmişler, yalnızca iki hastada gelişen siklops lezyonu ve ekstansiyon kaybı nedeniyle sekonder cerrahi uygulamışlardır. ${ }^{[21]}$

2019 yılında selektif AM ve PL rekonstrüksiyon yapılmış uzun süreli takibi olan 76 hastanın tedavi sonuçları yayımlanmıştır. IKDC (International Knee Documentation
Committee) ve Lysholm skorlarına göre iyi sonuç bildirilen çalışmada, ortalama 85 (65-110) aylık takip sonrasında \%2,6 başarısızlık bildirilmiştir. ${ }^{[22]}$ Literatürde parsiyel ÖÇB yaralanması sonrası, randomize kontrollü olarak konservatif ya da cerrahi tedavilerin karşılaştırıdığı bir çalışma bulunmamaktadır. Bu açıdan meta-analiz çalışmalarında, selektif tek demet rekonstrüksiyonun rutin olarak uygulanması önerilememektedir. ${ }^{[5]}$

\section{Anatomik total ÖÇB rekonstrüksiyonu}

Parsiyel ÖÇB yaralanmaları sonrasında cerrahi tedavi kararı verilen hastalarda, uygulanacak yönteme artroskopik muayene ile karar verilir. AM ya da PL demetin tam olarak korunmadığı parsiyel yaralanmalarda ya da cerrahın tedavi tercihine göre oluşan instabilitenin tedavisinde standart anatomik total ÖÇB rekonstrüksiyonu uygulanabilir. ${ }^{[1,5]} \mathrm{Bu}$ konuda cerrah tek demet ya da çift demet primer ÖÇB rekonstrüksiyonu tercih edebilir. Literatürde iki tekniğin primer uygulanması açısından benzer oranda başarılı sonuçlar bildirilmektedir. ${ }^{[23]}$ Cerrahi sırasında mevcut olan 
kalıntı (remnant) ÖÇB dokularının korunması tartışmalıdır. Bununla birlikte dokuların korunmasının mekanik, vasküler ve propriyoseptif açıdan yararlı olduğu düşünülmektedir. ${ }^{[24]}$

\section{SONUÇ}

Parsiyel ÖÇB yaralanmaları konusundaki tanım, doğal seyir ve tedavi tartışmaları halen sürmektedir. ${ }^{[3]}$ Hastaların tedavi kararında; hastanın yaşı, sportif aktivite seviyesi ve beklentisi, yaralanma zamanı, bağın yaralanma miktarı gibi birçok faktör göz önünde bulundurularak, hasta bazlı bir değerlendirme ile karar verilmelidir. ${ }^{[2,12]}$ Genel olarak rutin bir tedavi protokolü üzerinde fikir birliği (konsensus) bulunmamaktadır. Buna rağmen, düşük beklentili ya da instabilite testleri silik olan ek yaralanması bulunmayan olgularda konservatif olarak izlem yapılmalıdır. Bu izlem sonrasında, klinik instabilitesi devam eden semptomatik hastalar cerrahi tedaviye alınmalıdır. Bununla birlikte, yapılan doğal seyir çalışmalarında yüksek oranda total rüptür ve yetmezlik geliştiği gözlenen, sportif aktivitesi ve beklentisi fazla, rotasyonel instabilitesi olan hastalarda, erken dönem cerrahi tedavi uygulamaları ön planda düşünülmelidir.

\section{KAYNAKLAR}

1. DeFranco MJ, Bach BR Jr. A comprehensive review of partial anterior cruciate ligament tears. J Bone Joint Surg Am 2009;91(1):198-208. Crossref

2. Sonnery-Cottet B, Colombet P. Partial tears of the anterior cruciate ligament. Orthop Traumatol Surg Res 2016;102(1 Suppl):S59-67. Crossref

3. Pujol N, Colombet P, Cucurulo T, Graveleau N, Hulet C, Panisset JC, Potel JF, Servien E, Sonnery-Cottet B, Trojani C, Djian P; French Arthroscopy Society (SFA). Natural history of partial anterior cruciate ligament tears: a systematic literature review. Orthop Traumatol Surg Res 2012;98(8 Suppl):S160-4. Crossref

4. Pujol N, Colombet P, Potel JF, Cucurulo T, Graveleau N, Hulet C, Panisset JC, Servien E, Sonnery-Cottet B, Trojani C, Djian P; French Arthroscopy Society (SFA). Anterior cruciate ligament reconstruction in partial tear: selective anteromedial bundle reconstruction conserving the posterolateral remnant versus single-bundle anatomic $\mathrm{ACL}$ reconstruction: preliminary 1-year results of a prospective randomized study. Orthop Traumatol Surg Res 2012;98(8 Suppl):S171-7. Crossref

5. Papalia R, Franceschi F, Zampogna B, Tecame A, Maffulli $N$, Denaro V. Surgical management of partial tears of the anterior cruciate ligament. Knee Surg Sports Traumatol Arthrosc 2014;22(1):154-65. Crossref

6. Petersen $\mathrm{W}$, Zantop $\mathrm{T}$. Anatomy of the anterior cruciate ligament with regard to its two bundles. Clin Orthop Relat Res 2007;454:35-47. Crossref

7. Amis AA. The functions of the fibre bundles of the anterior cruciate ligament in anterior drawer, rotational laxity and the pivot shift. Knee Surg Sports Traumatol Arthrosc 2012;20(4):613-20. Crossref
8. Kondo E, Merican AM, Yasuda K, Amis AA. Biomechanical analysis of knee laxity with isolated anteromedial or posterolateral bundle-deficient anterior cruciate ligament. Arthroscopy 2014;30(3):335-43. Crossref

9. Colombet P, Dejour D, Panisset J-C, Siebold R. Current concept of partial anterior cruciate ligament ruptures. Orthop Traumatol Surg Res 2010;96(8):S109-18. Crossref

10. Arnold JA, Coker TP, Heaton LM, Park JP, Harris WD. Natural history of anterior cruciate tears. Am J Sports Med 1979;7(6):305-13. Crossref

11. Noyes FR, Mooar LA, Moorman CT 3rd, McGinniss GH. Partial tears of the anterior cruciate ligament. Progression to complete ligament deficiency. J Bone Joint Surg Br 1989;71$B(5): 825-33$. Crossref

12. Robert H, Nouveau S, Gageot S, Gagniere B. A new knee arthrometer, the GNRB. experience in ACL complete and partial tears. Orthop Traumatol Surg Res 2009;95(3):171-6. Crossref

13. Duc SR, Zanetti M, Kramer J, Käch KP, Zollikofer CL, Wentz $\mathrm{KU}$. Magnetic resonance imaging of anterior cruciate ligament tears: evaluation of standard or- thogonal and tailored paracoronal images. Acta Radiol 2005;46(7):729-33. Crossref

14. Tjoumakaris FP, Donegan DJ, Sekiya JK. Partial tears of the anterior cruciate ligament: diagnosis and treatment. Am J Orthop (Belle Mead NJ) 2011;40(2):92-7.

15. Fitzgerald GK, Axe MJ, Snyder-Mackler L. Proposed practice guidelines for nonoperative anterior cruciate ligament rehabilitation of physically active individuals. J Orthop Sports Phys Ther 2000;30(4):194-203. Crossref

16. Dallo I, Chahla J, Mitchell JJ, Pascual-Garrido C, Feagin JA, LaPrade RF. Biologic Approaches for the Treatment of Partial Tears of the Anterior Cruciate Ligament: A Current Concepts Review. Orthop J Sports Med 2017;5(1):2325967116681724. Crossref

17. Fayard JM, Sonnery-Cottet B, Vrgoc G, O'Loughlin P, de Mont Marin GD, Freychet B, Vieira TD, Thaunat M. Incidence and Risk Factors for a Partial Anterior Cruciate Ligament Tear Progressing to a Complete Tear After Nonoperative Treatment in Patients Younger Than 30 Years. Orthop J Sports Med 2019;7(7):2325967119856624. Crossref

18. Indelli PF, Dillingham MF, Fanton GS, Schurman DJ. Monopolar thermal treatment of symptomatic anterior cruciate ligament instability. Clin Orthop Relat Res 2003;407:139-47. Crossref

19. Gipsman AM, Trasolini N, Hatch GFR 3rd. Primary Anterior Cruciate Ligament Single-Bundle Repair with Augmentation for a Partial Anterior Cruciate Ligament Tear. Arthrosc Tech 2018;7(4):e367-72. Crossref

20. Ochi M, Adachi N, Uchio Y, Deie M, Kumahashi N, Ishikawa $M$, Sera S. A minimum 2-year follow-up after selective anteromedial or posterolateral bundle anterior cruciate ligament reconstruction. Arthroscopy 2009;25(2):117-22. Crossref

21. Abat F, Gelber PE, Erquicia JI, Pelfort X, Tey M, Monllau JC. Promising short-term results following selective bundle reconstruction in partial anterior cruciate ligament tears. Knee 2013;20(5):332-8. Crossref

22. Perelli S, Ibañez F, Gelber PE, Erquicia JI, Pelfort X, Monllau JC. Selective Bundle Reconstruction in Partial ACL Tears Leads to Excellent Long-Term Functional Outcomes and a Low Percentage of Failures. Knee 2019;26(6):1262-70. Crossref

23. Desai N, Alentorn-Geli E, van Eck CF, Fu FH, Karlsson J, Samuelsson K. A systematic review of single- versus doublebundle $A C L$ reconstruction using the anatomic anterior cruciate ligament reconstruction scoring checklist. Knee Surg Sports Traumatol Arthrosc 2016;24(3):862-72. Crossref

24. Temponi EF, de Carvalho Júnior LH, Sonnery-Cottet B, Chambat P. Partial tearing of the anterior cruciate ligament: diagnosis and treatment. Rev Bras Ortop 2015;50(1):9-15. Crossref 